Document downloaded from:

http://hdl.handle.net/10251/46178

This paper must be cited as:

Moliner Cabedo, E.; Museros Romero, P.; Martínez Rodrigo, MDLD. (2012). Retrofit of existing railway bridges of short to medium spans for high-speed traffic using viscoelastic dampers. Engineering Structures. 40:519-528. doi:10.1016/j.engstruct.2012.03.016.

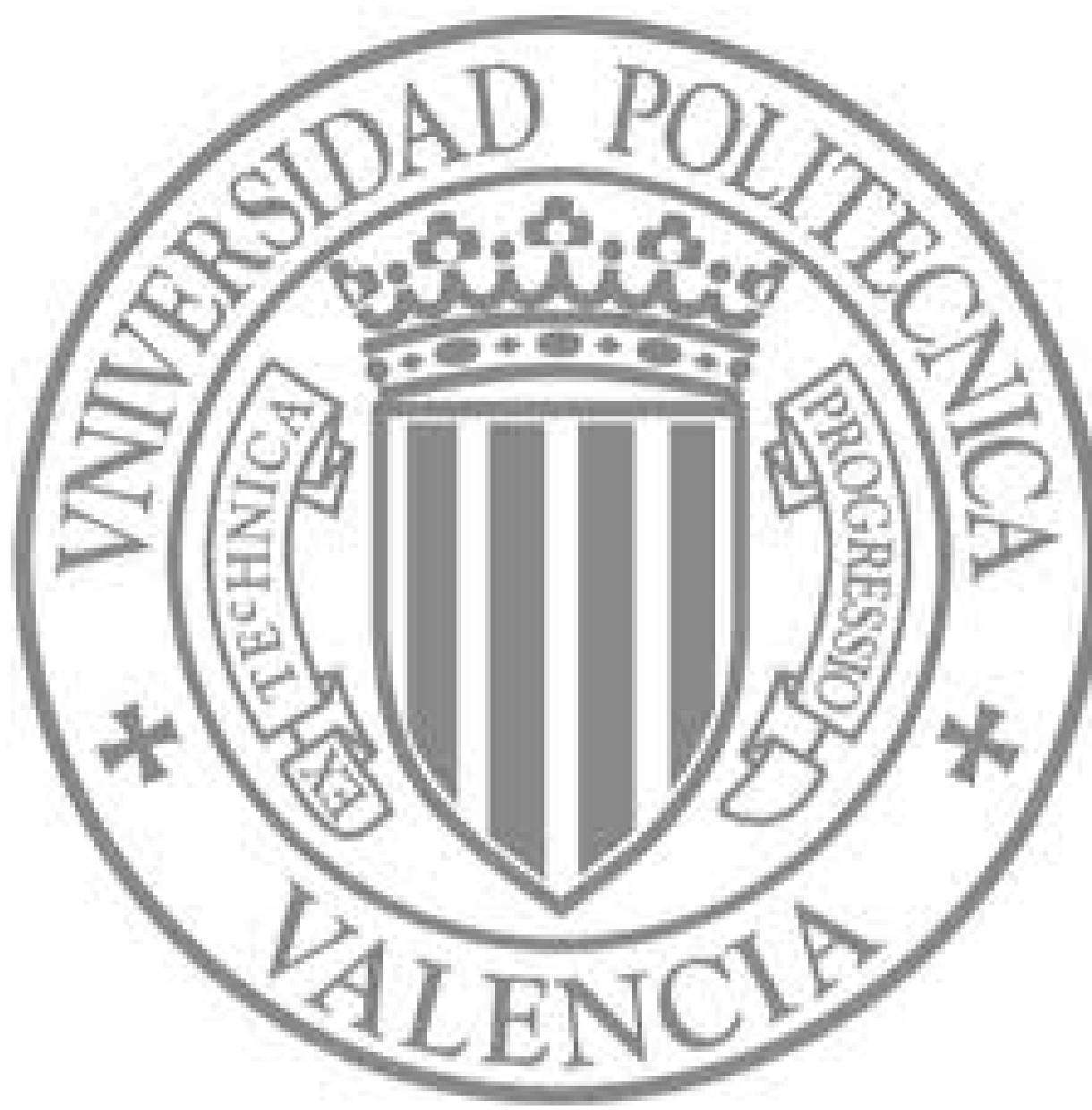

The final publication is available at

http://dx.doi.org/10.1016/j.engstruct.2012.03.016

Copyright Elsevier 


\title{
RETROFIT OF EXISTING RAILWAY BRIDGES OF SHOR TO MEDIUM SPANS FOR HIGH-SPEED TRAFFIC USING VISCOELASTIC DAMPERS
}

\author{
E. Moliner ${ }^{1 *}$, P. Museros ${ }^{2}$, M.D Martínez-Rodrigo' \\ ${ }^{1}$ Universitat Jaume I, Dpt. of Mechanical Engineering and Construction, 12071 Castellón, Spain \\ ${ }^{2}$ Universidad de Granada, Dpt. of Structural Mechanics and Hydraulic Engineering, 18071 Granada, Spain
}

\begin{abstract}
This paper presents a study on the energy-absorbing capacities of viscoelastic dampers (VEDs) for reducing the resonant vibrations of simply supported high-speed railway bridges of short to medium span. The proposed solution is based on retrofitting the bridge with a set of discrete VEDs connected to the slab and to an auxiliary structure, placed underneath the bridge deck and resting on the abutments. In this investigation attention is focused on mitigating flexural vibrations; therefore, both the bridge and the auxiliary structure are modelled as simply supported beams with Bernoulli-Euler (B-E) behavior, whereas a discrete fractional derivative model simulates the behavior of the damping material. Firstly, a parametric study of this planar model is carried out, which has led to a dimensioning procedure of the dissipative system. The technical feasibility of this particular retrofit design is numerically evaluated by applying it to a numerical model of a simply supported railway bridge with inadmissible vertical accelerations. Numerical results show that the dynamic response of the structure can be significantly reduced in resonance with the proposed damping system.
\end{abstract}

\footnotetext{
*(Correspondig author): Emma Moliner, Dpt. of Mechanical Engineering and Construction, Universitat Jaume I Avda Sos Baynat s/n, 12071-Castellón (Spain).

E-mail: molinere@emc.uji.es. Tel: +34964728131. Fax:+34964728106
} 


\section{INTRODUCTION}

The dynamic behaviour of railway bridges has become an issue of main concern between scientists and engineers over the last 20 years, due to the extensive construction of new HighSpeed lines and also the use of old lines for higher speeds.

Fast trains can induce resonance situations in railway bridges, being the short-to-mediumspan bridges where the main structural elements are simpy supported (S-S), the most critical in this regard. When the train travels at a resonant speed, high levels of the deck vertical acceleration are to be expected, which can result in adverse consequences such as ballast deconsolidation, passenger discomfort or higher risk of derailment. This fact has been reported by some members of the D-214 Committee of the European Rail Research Institute: Frýba [6] and Mancel et al. [13]. In such circumstances, the bridge deck has to be stiffened or replaced in order to keep the maximum vertical acceleration below the Serviceability Limit State of $3.5 \mathrm{~m} / \mathrm{s}^{2}$ for ballasted tracks [5], avoiding maintenance and security problems. Clearly, one major concern is the cost of the strengthening/replacement operations.

Several authors have evaluated the possibility of controlling high-speed trains induced vibrations in railway bridges with passive energy dissipation devices, as an alternative to the classical solutions (deck strengthening/replacement). Kwon et al. [11] and Wang et al. [24] have investigated the application of Tuned Mass Dampers (TMDs) for this purpose. Aside from passive TMDs, a couple of authors have also addressed the application of pure viscous dampers (FVDs) to reduce the amplification in beams traversed by moving loads, such as Oliveto et al. [21] and Museros and Martínez-Rodrigo [19, 15, 16]. In particular, the latter authors propose an alternative for the retrofit of existing bridges that show inadequate dynamic performance under the passage trains at higher speeds. The proposed retrofitting system consists of a simply supported auxiliary beam placed parallel to the main one (the one 
that supports the passage of the moving loads) and a set of linear FVDs that connect both beams at several sections. The authors conclude that there exists an optimum combination of auxiliary beam and value of the FVD constants that minimize the main beam response, and the proposed retrofitting system may apply to other situations where simply supported beams vibrate at resonance due to different causes.

From a practical point of view, it is also of interest to investigate the application of viscoelastic dampers (VEDs) to vibration control in high-speed railway bridges, due to its fine damping properties, cheap cost, simple construction and excellent performance in time for what concerns aging properties and maintenance [20]. The application of viscoelastic materials to civil engineering structures appears to have begun in 1969, when approximately 10000 viscoelastic dampers were installed in each of the twin towers of the World Trade Center in New York to reduce wind-induced vibrations [12]. Lately, they have been investigated for earthquake resistant design as a viable candidate to be incorporated either into new constructions or existing buildings on retrofit for earthquake hazard mitigation (for a detailed literature review see Samali and Kwok [22]). More recent outdoor applications can also be found in stay cables of short-span bridges, such as Traunsteg in Wels (Austria), or in the roof of Chien-Tan railroad Station in Taipei; both of them are related to the control of wind-induced vibrations. Particularly as regards its application to railway bridges, Choo et al. [4] propose the retrofit of long-span composite bridges (from 40 to $60 \mathrm{~m}$ ) with VEDs.

Viscoelastic dampers are normally made of viscoelastic material layers bonded with steel plates (Fig. 1.), and dissipate energy through shear deformation. The behavior of viscoelastic dampers is not purely viscous but exhibits also instantaneous elastic response; and is usually described by two main parameters: the Shear Storage Modulus, $G_{E}$ and the Loss Factor, $\eta$; both depend strongly on strain ratio, vibration frequency and temperature [9, 3], and many authors have investigated different models to simulate the VE behavior. A classical approach 
uses a mechanical model based on combinations of springs and dashpots elements, such as Maxwell model, the Kelvin-Voigt model, and complex combinations of them (see [1]). However the agreement with the observed behavior is usually poor, unless the model comprises an elevated number of parameters which renders the method rather cumbersome. A review of the literature indicates a predominant use of the fractional derivative model for viscoelastic dampers, since it is capable of characterizing broad-band viscoelastic behaviour with a small number of model constants [2]. For instance, Koh and Kelly [10] modelled elastomeric bearings using a fractional-order Kelvin model and observed the superiority of its performance to that of the standard Kelvin model. Also, Tsai and Lee [23] developed a model based on fractional derivatives in good agreement with experimental tests, and an advance finite element formulation for the viscoelastic damper to be implemented in a computer program.

In the present study we evaluate the retrofit of high speed railway bridges by using the model proposed by Tsai and Lee [23], which is capable of describing the material behavior at different temperature and deformation levels.

The approach adopted herein is based on three main facts: (i) In a large number of cases, the excessive vibrations in simply supported bridges are caused by resonances of the first bending mode; (ii) if the damping present in the structure were sufficiently high the amplitude of the first mode resonances would not exceed allowable limits. The required level of damping can be computed using simple dynamic analysis tools; (iii) when the retrofitting system is connected to the bridge, the dynamic behavior at resonance is similar to that of a one-degreeof-freedom (1-DOF) system subjected to harmonic load. Or in other words, the first bending mode is affected by the damping system approximately as if it were introducing an external increase of the bridge damping ratio. 
Therefore, a procedure can be devised in order to dimension the damping system in a first approach. Subsequently, an analysis is carried out with a view to discovering whether the required level of external damping has been reached. If this were so, the structure would satisfy the serviceability limits related to the vertical vibrations (accelerations) of the deck. Otherwise, the damping system is redimensioned following an iterative process until the maximum accelerations satisfy the serviceability limits.

\section{RETROFIT CONFIGURATION}

The configuration of the retrofitting system presented here is similar to the one presented in a previous work of Museros and Martínez-Rodrigo [19]. The difference comes from the use of VEDs instead of FVDs: in this work a set of VEDs link the bridge with the auxiliary beam, and the energy is dissipated through shear deformation. Unlike the FVDs, the VEDs do not only actuate as energy dissipaters, but they also modify the overall stiffness of the system. Fig. 2 shows a possible configuration of the retrofitting system.

The dissipative system consists of two main elements. The first element is an auxiliary steel or pre-stressed concrete beam placed under the slab, among the original girders of the bridge deck. The second is a set of VEDs that link the vertical motion of certain sections of both systems. The auxiliary beam is simply supported at the abutments and does not contact the slab at any intermediate section. Although Fig. 2 presents a hollow cross-section for the auxiliary beam, any other kind of section could be used.

The influence of the local deformation of the slab between two adjacent girders, a fact that could compromise the technical feasibility of this retrofitting system, was also studied by Martinez et. al in [15] using FVDs, concluding that the proposed solution enables the transmission of forces with no relevant loses of displacement. 


\section{PLANAR MODEL OF THE RETROFITTING SYSTEM}

The behavior of the bridge with the retrofitting system is modelled using a planar system: a simply supported Bernoulli-Euler (B-E) main beam, which represents the bridge deck, is connected to an auxiliary, simply supported B-E beam. The main and auxiliary beams rest directly on the abutments without any intermediate elastic bearing. In typical applications the auxiliary beam is placed underneath the main one, and a series of discrete VEDs link the vertical motion of certain sections of the beams. The resulting system is symmetric with respect to the mid-span section of the bridge.

As regards railway bridges, the results of the planar model are only applicable to single-track non-skewed bridges, since the torsion oscillations of beams subjected to eccentric moving loads are not taken into account. Nevertheless, single-track bridges, particularly medium to short span ones, are usually the most unfavorable cases found in practice due to their low linear mass, and in such structures it is highly likely that resonance will be related to oscillations of the first bending mode. Fig. 3 shows a scheme of the planar model used in this investigation.

In Fig. 3, $P_{k}$ and $d_{k}$ are the modulus and the distance from the $k$ th load to the beginning of the beam at $t=0$. The loads acting on the structure are assumed to be constant-valued.

The model adopted here to represent the behavior of VEDs is based on the work of Tsai and Lee [23], where the authors present an advanced finite element formulation for VEDs based on fractional derivatives which is in good agreement with experimental results. As a remarkable feature, this model is able to reproduce the decay of the material properties observed during the first cycles of oscillation, and also due to ambient temperature variations. In the mentioned reference, Tsai and Lee use this formulation to study the improvement of seismic resistance of buildings with VEDs. In the present work, we have applied the same 
approach to the retrofitting of high-speed railway bridges; a brief summary of the method follows.

From the fractional shear stress-strain relationship of a VED material [2],

$$
\tau(t)=G_{E} \gamma(t)+G_{C} D^{\alpha}[\gamma(t)]
$$

where $\tau(t)$ and $\gamma(t)$ are the shear stress and shear strain, $G_{E}, G_{C}$, are the two constitutive model parameters, and the term $D^{\alpha}[\gamma(\mathrm{t})]$ is the fractional derivative, defined as follows:

$$
D^{\alpha}[\gamma(t)]=\frac{1}{\Gamma(1-\alpha)} \frac{d}{d t} \int_{0}^{t} \frac{\gamma(\tau)}{(t-\tau)^{\alpha}} d \tau
$$

where $\Gamma(\cdot)$ is the gamma function and $0<\alpha<1$. The constitutive model parameters are

$$
\left.G_{E}=G_{C}=G=A_{0}\left\{1+\mu e^{-\beta\left[\int \tau d \gamma+\theta\left(T-T_{0}\right)\right.}\right]\right\}
$$

$A_{0}, \alpha, \beta, \mu$ y $\theta$ are coefficients of the viscoelastic material to be determined from the experimental data, and $T$ and $T_{0}$ stand for the ambient temperature and the reference temperature.

One can discretise equation (1) at time step $N \Delta t$ assuming linear variation of the shear strain $\gamma(\mathrm{t})$ between two consecutive time steps, $(n-1) \Delta t$ and $n \Delta t$. After doing so, it is rewritten as

$$
\tau(N \Delta t)=\left[G+\frac{G(\Delta t)^{-\alpha}}{\Gamma(2-\alpha)}\right] \gamma(N \Delta t)+\frac{G(\Delta t)^{-\alpha}}{\Gamma(2-\alpha)} H(N \Delta t) .
$$

The term $H(N \Delta t)$, called the previous time effect of the strain, is

$$
\begin{aligned}
& H(N \Delta t)=\left[(N-1)^{1-\alpha}+(-N+1-\alpha) N^{-\alpha}\right] \gamma(0)+ \\
& +\sum_{n=1}^{N-1}\left[-2(N-n)^{1-\alpha}+(N-n+1)^{1-\alpha}+(N-n-1)^{1-\alpha}\right] \gamma(n \Delta t),
\end{aligned}
$$

where $\gamma(\cdot)$ is the shear strain of the VED. The term $H(N \Delta t)$ depends on the whole time history of the system and therefore has a significant computational cost. However, when dynamical 
oscillating responses are considered, it is possible to truncate the displacement history considering only the most recent one [8]. Finally, according to Tsai and Lee [23], the damper force at time step $t=N \Delta t$ along the $y$ direction is

$$
F_{D}(N \Delta t)=K_{D} D(N \Delta t)+F_{V}(N \Delta t)
$$

where $K_{D}$ is

$$
K_{D}=\frac{S}{h} G\left(1+\frac{(\Delta t)^{-\alpha}}{\Gamma(2-\alpha)}\right)
$$

and $S$ and $h$ are the shear area and thickness of the VED respectively. The previous time effect of the equivalent VED force, $F_{V}(N \Delta t)$, and the VED elongation, $D(N \Delta t)$, are given by

$$
\begin{gathered}
F_{V}=\frac{G(\Delta t)^{-\alpha}}{\Gamma(2-\alpha)} H(N \Delta t) S, \\
D=y_{B}\left(x_{D i}^{B}\right)-y_{b}\left(x_{D i}^{b}\right) .
\end{gathered}
$$

Subscripts $B$ and $b$ indicate the vertical displacement of the VED end in contact with the main and auxiliary beam, respectively, and $x_{D i}$ is the location of the $i$ th damper along the $\mathrm{X}$ axis of the main beam. The shear strain $\gamma(N \Delta t)$ is computed as

$$
\gamma(N \Delta t)=\frac{D(N \Delta t)}{h}
$$

\section{GOVERNING EQUATIONS OF MOTION OF THE RETROFITTING SYSTEM SUBJECTED TO MOVING LOADS}

Several authors, such as Frýba [6, 7], Yang et al. [25] or Museros and Alarcón [18] have presented the partial differential equation governing the flexural behaviour of a simply supported beam subjected to a train of concentrated loads. However, if we introduce an auxiliary beam with several VEDs connecting both beams, the governing equations of motion 
need to be modified. The motion is obtained as the superposition of $N_{B}$ and $N_{b}$ modes for the main and auxiliary beams, respectively. The presence of VEDs linking the oscillations in some sections of the beams causes the modal equations of this two structural elements to be coupled; for this reason, the time-histories of the modal contributions taken into account are a function of the order of the modal system of equations (i.e. they are a function of $N_{B}$ and $N_{b}$ ). When a particular bridge is analyzed, a sensitivity analysis is carried out to determine whether the response has converged for the values of $N_{B}$ and $N_{b}$ used in the calculations.

The system of equations of the retrofitting system, written in matrix form and in modal coordinates is

$$
\mathbf{M} \ddot{\xi}(t)+\mathbf{C} \dot{\xi}(t)+\mathbf{K} \xi(t)+\mathbf{R}^{T} \mathbf{K}_{D}(t) \mathbf{R} \xi(t)+\mathbf{R}^{T} \mathbf{F}_{V}(t)=\mathbf{Q}(t) .
$$

The column vector of modal displacements, which are the unknowns, is

$$
\xi(t)=\left(\begin{array}{llllll}
\xi_{1}^{B} & \cdots & \xi_{N_{B}}^{B} & \xi_{1}^{b} & \cdots & \xi_{N_{b}}^{b}
\end{array}\right)^{T}
$$

This system of equations will be numerically integrated with an implicit predictor-corrector method. The total number of equations, or dimension of the modal space, is equal to $N_{B}+N_{b}$. In general superscripts $B$ and $b$ indicate magnitudes associated to the main and auxiliary beam respectively. $\mathbf{M}, \mathbf{C}$ and $\mathbf{K}$ are the mass, damping and stiffness square matrices of the system in modal coordinates,

$$
\mathbf{M}=\left(\begin{array}{cc}
\mathbf{M}_{B} & \mathbf{0} \\
\mathbf{0} & \mathbf{M}_{b}
\end{array}\right)_{N_{B}+N_{b}}, \mathbf{C}=\left(\begin{array}{cc}
\mathbf{C}_{B} & \mathbf{0} \\
\mathbf{0} & \mathbf{C}_{b}
\end{array}\right)_{N_{B}+N_{b}}, \mathbf{K}=\left(\begin{array}{cc}
\mathbf{K}_{B} & \mathbf{0} \\
\mathbf{0} & \mathbf{K}_{b}
\end{array}\right)_{N_{B}+N_{b}} .
$$

Where

$$
\begin{aligned}
& \mathbf{M}_{B}=\left[M_{B, i i}\right]=\frac{m_{B} L_{B}}{2}, \quad i=1,2, \ldots N_{B}, \quad \mathbf{M}_{b}=\left[M_{b, i i}\right]=\frac{m_{b} L_{b}}{2}, \quad i=1,2, \ldots N_{b}, \\
& \mathbf{C}_{B}=\left[C_{B, i i}\right]=\zeta_{i}^{B} \omega_{i}^{B} m_{B} L_{B}, \quad i=1,2, \ldots N_{B}, \quad \mathbf{C}_{b}=\left[C_{b, i i}\right]=\zeta_{i}^{b} \omega_{i}^{b} m_{b} L_{b}, \quad i=1,2, \ldots N_{b},
\end{aligned}
$$


$\mathbf{K}_{B}=\left[K_{B, i i}\right]=\left(\omega_{i}^{B}\right)^{2} m_{B} L_{B}, \quad i=1,2, \ldots N_{B}, \quad \mathbf{K}_{b}=\left[K_{b, i i}\right]=\left(\omega_{i}^{b}\right)^{2} m_{b} L_{b}, \quad i=1,2, \ldots N_{b}$,

In the previous equations, $m$ and $L$ are, respectively, the linear mass and length of the beams; and $\omega_{\mathrm{i}}, \zeta_{\mathrm{i}}$ stand for the modal frequency and damping.

$\mathbf{R}$ is the transformation matrix which transforms the modal coordinates $\xi(t)$ into elongations of the dampers $\mathbf{D}(t), \mathbf{D}(t)=\mathbf{R} \xi(t)$

$$
\left(\begin{array}{c}
D_{1} \\
D_{2} \\
\vdots \\
D_{N_{d}}
\end{array}\right)=\left[\begin{array}{cccccc}
\sin \frac{\pi x_{1}^{B}}{L_{B}} & \cdots & \sin \frac{N_{B} \pi x_{1}^{B}}{L_{B}} & -\sin \frac{\pi x_{1}^{b}}{L_{b}} & \cdots & -\sin \frac{N_{b} \pi x_{1}^{b}}{L_{b}} \\
\sin \frac{\pi x_{2}^{B}}{L_{B}} & \cdots & \sin \frac{N_{B} \pi x_{2}^{B}}{L_{B}} & -\sin \frac{\pi x_{2}^{b}}{L_{b}} & \cdots & -\sin \frac{N_{b} \pi x_{2}^{b}}{L_{b}} \\
\vdots & & \vdots & \vdots & \vdots \\
\sin \frac{\pi x_{N_{d}}^{B}}{L_{B}} & \cdots & \sin \frac{N_{B} \pi x_{N_{d}}^{B}}{L_{B}} & -\sin \frac{\pi x_{N_{d}}^{b}}{L_{b}} & & -\sin \frac{N_{b} \pi x_{N_{d}}^{b}}{L_{b}}
\end{array}\right]\left(\begin{array}{c}
\xi_{1}^{B} \\
\vdots \\
\xi_{N_{B}}^{B} \\
\xi_{1}^{b} \\
\vdots \\
\xi_{N_{b}}^{b}
\end{array}\right)
$$

The elongations of each of the $N_{d}$ dampers installed in the retrofitting system are $D_{1}$, $D_{2}, \ldots D_{N_{d}}$, and $x_{1}, x_{2}, \ldots x_{N_{d}}$ are the locations of each of the VEDs, measured along the $\mathrm{X}$ direction of the main or auxiliary beams.

In equation (9), $\mathbf{K}_{D}$ and $\mathbf{F}_{V}$ contain the VED terms of the fractional model, defined in equations (7):

$$
\mathbf{K}_{D}=\left[\begin{array}{ccc}
K_{D}^{1} & & 0 \\
& \ddots & \\
0 & & K_{D}^{N_{d}}
\end{array}\right], \quad \mathbf{F}_{V}=\left(\begin{array}{lll}
F_{V}^{1} & \cdots & F_{V}^{N_{d}}
\end{array}\right)^{T} .
$$

Finally, $\mathbf{Q}(t)$ is the vector of moving modal forces, defined as

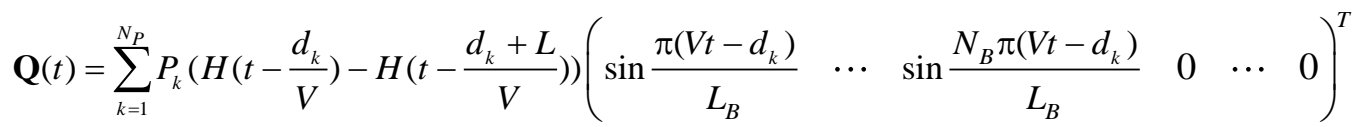


where $N_{P}$ is the total number of axle loads, $P_{k}$ is the value of the $k$ th load and $H\left(t-t_{0}\right)$ is the Heaviside unit function acting at time $t_{0} . V$ stands for the constant train speed and $d_{k}$ is the initial distance from the $k$ th load to the beginning of the beam.

As it can be seen, equation (9) is a non-linear coupled system of equations that is solved by mode superposition and numerically integrated using a predictor-corrector method.

\section{SENSITIVITY ANALYSIS}

\subsection{SIMPLIFIED EQUIVALENT SYSTEM WITH TWO DEGREES OF FREEDOM SUBJECTED TO HARMONIC EXCITATION}

In order to identify the main governing parameters of the damping system and how they affect its dynamic behaviour, the planar model shown in Fig. 3 will be first analyzed under the action of a harmonically varying force, which is able to capture the essential features of the system behavior at resonance. The following assumptions will be considered in the planar model for this study: (i) the main and auxiliary beams are vertically aligned and their lengths are equal; (ii) in single-track bridges it is more likely that resonance is related to oscillations of the first bending mode [18]; therefore, only the first flexural mode of the main beam will be taken into account in the computation of the dynamic response. Also, the oscillations of this fundamental mode tend to create a symmetric distribution of damper forces with respect to the mid-span section, which excite the movement of the auxiliary beam. Consequently, the auxiliary beam will be analyzed in a first approach considering the sole contribution of its first bending mode; (iii) as for the VED, a simpler numerical model will be used, the so-called Kelvin model, which consists of a spring-dashpot system connected in parallel with constantvalued model parameters. Therefore, the evolutionary behavior of VE material subjected to variations of temperature, strain and frequency is not considered in this first approach. 
Assuming the previous hypotheses, the dynamic response of the retrofitted bridge at resonance can be approximately described by means of the two degrees of freedom (2-DOF) system shown in Fig. 4, expressed in modal space coordinates.

Since only the first mode of both beams is considered, any number of VEDs located at different sections is equivalent to a single VED located at mid-span, with $C_{D}$ and $K_{D}$ as the equivalent constants of the dashpot and spring element. The expression of the equivalent parameters $C_{D}$ and $K_{D}$ can be written as

$$
\begin{aligned}
C_{D} & =\frac{G_{E} \eta A_{V E D}}{\omega_{B} h_{V E D}} \sum_{i=1}^{N_{D}} \sin ^{2}\left(\frac{\pi x_{D i}}{L}\right), \\
K_{D} & =\frac{C_{D} \omega_{B}}{\eta} .
\end{aligned}
$$

and the shear-strain relationship is, therefore, $\tau(t)=G_{E} \gamma(t)+G_{C} \dot{\gamma}(t)$.

In equations (11), all the VED are considered to be identical (same material and properties) and symmetrically distributed between both beams with respect to the mid-span section. $G_{E}$ and $\eta$ are, respectively, the Shear Storage Modulus and the Loss Factor of the VE material, evaluated at a constant temperature and frequency; $A_{V E D}$ and $h_{V E D}$ are, respectively the shear area and thickness of the VED layers of material; $\omega_{B}$ is the fundamental circular frequency of the main beam; $N_{D}$ is the total number of VEDs, and $x_{i}$ and $L$ are, respectively, the location of the $i$ th damper measured along $\mathrm{X}$ axis and the length of each beam.

The definition of the following dimensionless ratios

$$
\begin{array}{ll}
\text { Frequency ratio: } & \varphi=\omega_{\mathrm{b}} / \omega_{\mathrm{B}} \\
\text { Excitation frequency ratio: } & \Omega=\omega_{f} / \omega_{B} \\
\text { Mass ratio: } & \mu=m_{b} / m_{B} \\
\text { Supplemental damping ratio: } & \zeta_{D}=C_{D} /\left(\omega_{B} m_{B} L\right) \\
\text { Supplemental stiffness ratio: } & \kappa_{D}=2 K_{D} /\left(\omega_{B}^{2} m_{B} L\right)
\end{array}
$$

leads to a dimensionless expression of the equations of motion of the 2-DOF system subjected to harmonic excitation 


$$
\left[\begin{array}{ll}
1 & 0 \\
0 & \mu
\end{array}\right]\left(\begin{array}{l}
\ddot{\xi}_{B} \\
\ddot{\xi}_{b}
\end{array}\right)+2 \omega_{B}\left[\begin{array}{cc}
\zeta_{B}+\zeta_{D} & -\zeta_{D} \\
-\zeta_{D} & \zeta_{b} \varphi \mu+\zeta_{D}
\end{array}\right]\left(\begin{array}{l}
\dot{\xi}_{B} \\
\dot{\xi}_{b}
\end{array}\right)+\omega_{B}^{2}\left[\begin{array}{cc}
1+\kappa_{D} & -\kappa_{D} \\
-\kappa_{D} & \varphi^{2} \mu+\kappa_{D}
\end{array}\right]\left(\begin{array}{l}
\xi_{B} \\
\xi_{b}
\end{array}\right)=\left(\begin{array}{c}
-\frac{2 P_{0}}{m_{B} L} \cos \left(\omega_{f} t\right) \\
0
\end{array}\right) .
$$

In the previous equations, subscripts $B$ and $b$ indicate magnitudes associated to the main and auxiliary beam respectively; $\xi_{B}$ and $\xi_{b}$ are the amplitudes of the first flexural mode in each beam; $m_{B}$ and $m_{b}$ are the linear masses of the beams; and $\zeta_{B}$ and $\zeta_{b}$, are their modal viscous damping ratios.

If resonance is induced by a train of a large number of loads (as the high-speed trains), the maximum response will correspond to the steady-state vibration. The forced solution of equation (18) leads to the following expression of the forced modal amplification of the main beam, divided by the static deflection caused by the concentrated load $P_{0}$,

$$
A_{B}=\sqrt{\frac{\left[\mu\left(\varphi^{2}-\Omega^{2}\right)+\kappa_{D}\right]^{2}+4 \Omega^{2}\left(\zeta_{b} \varphi \mu+\zeta_{D}\right)^{2}}{E^{2}+4 \Omega^{2} F^{2}}}
$$

being

$$
\begin{gathered}
E=\mu\left(\varphi^{2}-\Omega^{2}\right)\left(1-\Omega^{2}+\kappa_{D}\right)+\left(1-\Omega^{2}\right) \kappa_{D}-4 \Omega^{2}\left[\zeta_{b} \varphi \mu\left(\zeta_{B}+\zeta_{D}\right)+\zeta_{D} \zeta_{B}\right], \\
F=\zeta_{b} \varphi \mu\left(1-\Omega^{2}+\kappa_{D}\right)+\mu\left(\varphi^{2}-\Omega^{2}\right)\left(\zeta_{B}+\zeta_{D}\right)+\zeta_{D}\left(1-\Omega^{2}\right)+\zeta_{B} \kappa_{D} .
\end{gathered}
$$

The main beam modal acceleration is also of great interest, because of its relation with ballast stability. In the steady-state the nondimensional amplitude of the acceleration $a_{B}$ is:

$$
a_{B}=\Omega^{2} A_{B}
$$

Equation 19 shows that the response of the main beam depends on the following six parameters: $\Omega, \varphi, \mu, \zeta_{D}, \zeta_{B}$ and $\zeta_{b}$, since $\kappa_{D}$ can be calculated with this alternative expression:

$$
\kappa_{D}=\frac{2}{\eta\left(\omega_{B}\right)} \zeta_{D} .
$$




\subsection{SENSITIVITY PLOTS}

In order to visualize how the governing parameters of this system affect the main beam dynamic amplification and modal acceleration, $A_{B}$ and $a_{B}$, the response of this beam has been computed as a function of $\Omega$ for different values of the nondimensional parameters. Some of these results are shown in Fig. 5. Except for Fig 5f, in all plots the structural damping ratios of the main and auxiliary beam are $2 \%$ and $0.5 \%$ respectively.

Figs. $5 \mathrm{a}$ and $5 \mathrm{~b}$ show the acceleration $a_{B}$ versus $\Omega$; the family of curves have been obtained by increasing solely $\zeta_{D}$, which represents an increase in the area (or number) of VED, and with a VE material loss factor, $\eta$, of 1.2. The following behaviour is observed: (i) as the damper constant $C_{D}$ increases and so does $\zeta_{\mathrm{D}}$ (and also $\kappa_{D}$ ), the maximum response decreases monotonically until a minimum value is reached, and increases again if the damper constant keeps increasing; (ii) the value of $\Omega$ for which resonance occurs shifts sideways depending on the frequency ratio $\varphi$ : if the stiffness of the auxiliary beam is higher than the one of the main beam, $\varphi>1$, the maximum peak response shifts to the right, and if $\varphi<1$, it shifts to the left. Consequently, for each value of $\eta$ and $\mu$ there is an optimum value of $\zeta_{D}$ which leads to the minimum value of the maximum amplification. Although not depicted here, a similar behavior is observed for the dynamic amplification $A_{B}$.

Figs. $5 \mathrm{c}$ and $5 \mathrm{~d}$ gather the influence of the mass ratio, $\mu$, in the acceleration $a_{b}$, as the ratio of frequencies, $\varphi$, damping ratio $\zeta_{D}$, and loss factor $\eta$ remain constant $\left(\varphi=1.9-0.5, \zeta_{D}=0.12, \eta=\right.$ 1.2). The main beam acceleration decreases monotonically as $\mu$ increases. The minimum $a_{B}$ would correspond, therefore, with an infinity value of $\mu$. In that case the main beam behaves as if it were attached through the external damper to a fixed reference.

In Fig $5 \mathrm{e} a_{B}$ is plotted versus $\Omega$ for fixed values of $\mu, \zeta_{D}$ and $\eta$, showing the influence of the frequency ratio $\varphi$ in the response. The maximum $a_{B}$ is attained when $\varphi=1$, since both masses 
tend to vibrate in phase; whereas the reductions obtained with $\varphi>1$ can be higher than the reductions obtained with $\varphi<1$.

Finally, Fig 5f show the influence of the VE material loss factor, $\eta$, in the reduction of the response. As $\eta$ increases, the maximum peak response decreases and shifts to the left, due to the reduction of $k_{D}$ according to equation 22 .

The following conclusions can be extracted from this analysis: (i) for each value of $\eta$ and $\mu$ there is an optimum $\zeta_{D}$ which leads to the minimum value of the maximum acceleration, as it was also pointed out in [19]; (ii) the amplification $A_{B}$ has a similar behavior, but the value of $\zeta_{D}$ which is optimal for the acceleration is slightly different from the optimal one for the amplification; (iii) the two resonant peaks expected for the system are not perceptible, and the response is similar to the one expected for a one degree of freedom system (1-DOF). This has been confirmed in the ranges of interest of these parameters $(1.5 \leq \varphi \leq 2.5,0.05 \leq \mu \leq 0.3,0 \leq$ $\zeta_{B} \leq 0.05,0 \leq \zeta_{b} \leq 0.05$ ); (iv) previous point (iii) could be used to estimate the total amount of damping that the retrofitting system can introduce in the bridge: since $\zeta_{D}$ would only be a measurement of the damping ratio introduced in the main beam in case it were linked to a fixed reference (floor) by means of the VEDs, an estimation of the effective damping ratio can be obtained by calculating the properties of an equivalent 1-DOF system which has the same amplification at resonance as the 2-DOF at the same excitation frequency. To this end, one can use the following expressions:

$$
\zeta_{1-D O F}=\sqrt{\frac{A_{B}^{R}-\sqrt{\left(A_{B}^{R}\right)^{2}-1}}{2 A_{B}^{R}}}, \omega_{1-D O F}=\Omega_{R} \omega_{B} \sqrt[4]{\frac{\left(A_{B}^{R}\right)^{2}}{\left(A_{B}^{R}\right)^{2}-1}},
$$

being $A_{B}^{R}$ and $\Omega_{\mathrm{R}}$ the amplification of the 2-DOF system and the excitation frequency ratio at resonance, respectively. 


\section{DIMENSIONING PROCEDURE OF THE DAMPING SYSTEM: RETROFIT OF VINIVAL BRIDGE}

As an example of the application of VEDs to the retrofit of railway bridges, the dynamic behavior of a simply supported, single-track bridge due to the passing of High-Speed trains is analyzed with a view to assessing the effectiveness of the retrofitting system.

Vinival is a $9.70 \mathrm{~m}$ single bay simply supported railway bridge belonging to the Spanish railway network. The structure is composed by four independent decks, the outermost ones support the sidewalks and the two inner ones carry the ballasted tracks, as shown in Fig 6 . The only difference between the inner decks is the track eccentricity, being the less eccentric one $(0.25 \mathrm{~cm})$ the deck selected for the subsequent dynamic analyses, since the eccentricity is not considered in a planar model.

The main mechanical properties of the bridge are gathered in Table 1. This bridge has been selected because it is expected that the vertical acceleration will exceed the upper limit given by Eurocode [5], for ballasted tracks $\left(3.5 \mathrm{~m} / \mathrm{s}^{2}\right)$ due to its short length and low mass.

At first, the dynamic response of Vinival bridge is computed considering B-E behaviour, under the circulation of the HSLM-A trains from Eurocode 1 and seven European High-Speed trains: THALYS, TGV, ETR-Y, ICE2, EUROSTAR, VIRGIN and the Spanish TAV, in the range of velocities $[144,306] \mathrm{km} / \mathrm{h}$ discretized in $3.6 \mathrm{~km} / \mathrm{h}$ steps. The response in terms of accelerations for each train and circulating velocity is obtained in the time domain by modal superposition, accounting for modes under $30 \mathrm{~Hz}$, as per European Standards [5]. Fig. 7 shows the acceleration envelopes in the main beam for every circulating velocity and load model. 
The maximum vertical acceleration reaches $6.14 \mathrm{~m} / \mathrm{s}^{2}$ under the circulation of the composition HSLM-A2 at $220 \mathrm{~km} / \mathrm{h}$, corresponding to a fourth resonance of its first bending mode.

The optimization procedure of the damping system able to reduce the maximum vertical deck acceleration below $3.5 \mathrm{~m} / \mathrm{s}^{2}$, is an iterative process consisting on finding the smallest dimension of an auxiliary beam, which combined with the optimum VED size, keeps the acceleration below $3.5 \mathrm{~m} / \mathrm{s}^{2}$ in the main beam [17]. The following subsections summarize the steps performed.

\subsection{ESTIMATION OF THE DAMPING REQUIREMENTS IN THE BRIDGE}

As Martínez-Rodrigo and Museros propose [19], the maximum response of the bridge under the circulation of the bare train composition (HSLM-A2) is recalculated by increasing the structural damping ratio of the bridge progressively, until the acceleration falls below $3.5 \mathrm{~m} / \mathrm{s}^{2}$. The results are shown in Fig. 8.

It is well known that viscoelastic material properties are temperature dependent, and the energy-absorbing capacities of VEDs decrease as a result of rising ambient temperature. Consequently, the optimum combination of retrofitting elements at a certain ambient condition is not the optimal selection for a different one. As Fig. 5a indicates, if the damper constants are somewhat higher than the optimum values, only a slight decrease in the system performance is observed. This kind of behaviour gives engineers enough margin for finding a suitable damper-beam combination valid for a variable-temperature environment. Considering a range of temperatures of performance between 0 and $40^{\circ} \mathrm{C}$, the way of proceeding in order to find such a combination could be the selection of the optimum damping system able to achieve a reduction in the acceleration of $30 \%$ below the Serviceability Limit State of 3.5 $\mathrm{m} / \mathrm{s}^{2}$ at the average temperature of the interval $\left(20^{\circ} \mathrm{C}\right)$. As Fig. 8 shows, the structural 
damping requirement to achieve this reduction is $\zeta_{B}=5.5 \%$. Since in the retrofitted bridge the structural damping is estimated by means of an equivalent 1-DOF (equation 23 ), $\zeta_{1-D O F}=5.5 \%$.

\subsection{SELECTION OF THE MINIMUM SIZE OF THE AUXILIARY BEAM AND OPTIMUM DAMPER}

At this stage a VE material is chosen first; its properties should be optimal at $20^{\circ} \mathrm{C}$ and at a frequency equal to the fundamental frequency of the bridge $(12.8 \mathrm{~Hz})$. For this particular case, the VE material presented in the work of Tsai et. al. [23] has been selected, whose fractional model parameters are gathered in Fig. 9. This figure also shows in grey trace the hysteretic curve of this $\mathrm{VED}$ at $20^{\circ} \mathrm{C}$ while a sinusoidal shear strain of realistic amplitude 0.05 at a frequency equal to the natural frequency of the bridge, $12.8 \mathrm{~Hz}$, is induced; this evolutionary behavior has been predicted with the fractional derivative model. In black trace, the approximate equivalent hysteretic behaviour of a Kelvin model is also included, whose main model parameters $\left(G_{E}, \eta\right)$ at the same conditions of temperature, shear strain and frequency are gathered as well.

Two pre-stressed, identical concrete I members are selected to form the auxiliary beam system, with $E_{b}=36 \mathrm{MPa}$ and $\zeta_{b}=1 \%$. They are to be placed underneath the deck, symmetrically at each side of the track axis, so that if resonance of a bending mode occurs (most likely the fundamental one as shown in [18]), they act in phase as a single beam with double mass.

The sectional properties of the selected beams only depend on the beam height, $h$. Therefore, the dimensionless ratios $\varphi$ and $\mu$ defined in equations (13) and (15) are both dependent on $h$ and could be rewritten as 


$$
\mu(h)=\frac{m_{b}}{m_{B}}=\frac{\rho_{b} A_{b}(h)}{m_{B}}, \varphi(h)=\frac{\omega_{b}}{\omega_{B}}=\sqrt{\frac{E_{b} I_{z b}(h)}{\mu(h) E_{B} I_{z B}}} .
$$

Consequently, the six governing parameters of the 2-DOF system defined in section 5.1, $\Omega, \varphi$, $\mu, \zeta_{D}, \zeta_{B}$ and $\zeta_{b}$, change to $\Omega, h, \zeta_{D}, \zeta_{B}$ and $\zeta_{b}$. As the bridge properties are known, and also $\zeta_{b}$ and the properties of the VED Kelvin model at $20^{\circ} \mathrm{C}$ (Fig. 9), the acceleration of the main beam in the 2-DOF system of Fig. 4 can be computed for different retrofitting systems, each one defined by a pair $\left(h, \zeta_{D}\right)$, with $h$ varying between 0.7 and $1.3 \mathrm{~m}$, and $\zeta_{D}$ between 0 and 0.4 . The results of this sensitivity analysis are gathered in Fig. 10.

Fig $10 \mathrm{~b}$ shows the maximum values of $a_{B}$ computed with the 2-DOF, with $h$ ranging from 0.7 to $1.3 \mathrm{~m}$ and $\zeta_{D}$ from 0 to 0.4 . The dotted black trace indicates the optimum pairs $h-\zeta_{D}$, which produce the minimum maximum acceleration at resonance. As it can be seen, once the size $h$ of the auxiliary beam is fixed, the acceleration of the system decreases while $\zeta_{D}$ is increased. But when the dotted line is reached (the optimum $\zeta_{D}$ for the selected $h$ ), the increase of $\zeta_{D}$ produces a progressive increase of the response of the system. Also the damping ratio of the equivalent 1-DOF system defined by equations (23) is computed at each point of the dotted black trace. As stated before, this is referred to as effective damping ratio. Therefore, the effective damping ratio that the optimum combination $h-\zeta_{D}$ introduces in the main beam is obtained and plotted in Figure 10a. Using Figure 10a a value $h=1.07 \mathrm{~m}$ is obtained for the auxiliary beam to achieve an effective damping ratio equal to $5.5 \%$ at $20^{\circ} \mathrm{C}$. Finally, with the help of Fig. 10b, the optimum value of $\zeta_{D}$ associated to the selected beam height, $h=1.07 \mathrm{~m}$, is selected $\left(\zeta_{D}=8.8 \%\right)$. Once the size of the auxiliary beam and the supplemental damping ratio is chosen, the number of VEDs, dimensions, and locations can be selected so that the value of $\zeta_{D}=8.8 \%$ is reached. 


\subsection{OPTIMIZATION OF THE DAMPING SYSTEM IN THE TEMPERATURE}

\section{RANGE}

The previous results give an approximate estimation of the dimensions required for the retrofitting system at $20^{\circ} \mathrm{C}$. Subsequently, the dynamic behavior of the retrofitted bridge needs to be computed again by using the fractional VED model, under the passage of the same train compositions, and at different temperatures within the range of interest. Due to the coupling of the dynamic equations through the damping and stiffness matrices (equation 9), the accuracy of the modal responses increases with the order of the system of equations. A sensitivity analysis of the number of modes required is performed first ensuring the convergence of the modal responses. Fig. 11 presents the main characteristics selected for the damping system (obtained from the dimensioning procedure explained in the previous section). Details of how the beams and dampers are placed and connected to the deck would depend on the precise typology of the bridge.

In the retrofitted case four bending modes of the main beam are included in the problem formulation in modal space, along with the first two bending modes of the auxiliary concrete beams, which are merged into a single auxiliary beam in the planar model of Fig. 3 . Subsequently, the response of the main beam is computed from the sole contribution of its first bending mode because the higher ones have frequencies above $30 \mathrm{~Hz}$. In Fig. 12 the envelope of maximum acceleration for all velocities under the circulation of the most unfavourable train composition HSLM-A2 is presented. Different temperatures within the range have been considered. As it can be seen, at $0^{\circ} \mathrm{C}$ the maximum acceleration reaches 4.06 $\mathrm{m} / \mathrm{s}^{2}$; in this case the performance of the system is less efficient, since the damper dimensions are somewhat higher than the optimum values. Despite the aforementioned drawback, a reduction of $33.9 \%$ in maximum acceleration is attained. At $20^{\circ} \mathrm{C}$ the maximum acceleration 
in the main beam attains $2.84 \mathrm{~m} / \mathrm{s}^{2}$, and a value of $3.6 \mathrm{~m} / \mathrm{s}^{2}$ is reached at $40^{\circ} \mathrm{C}$. The controlling effect of the retrofitting system is apparent, as well as the influence of the ambient temperature in its energy absorbing capacities. In a view to achieve a better performance in a wide range of temperatures, the damping system can be redimensioned following an iterative process where the height of the auxiliary beam $h$ is increased until the maximum accelerations at $0^{\circ} \mathrm{C}$ and $40^{\circ} \mathrm{C}$ are kept below the desired limits.

Fig. 13a shows the maximum envelopes of accelerations attained in the retrofitted bridge under the passage of HSLM-A2 train model, with an auxiliary beam size $h=1.2 \mathrm{~m}$ (close to the original one, $1.07 \mathrm{~m}$ ), and with the VEDs dimensions and locations outlined in Fig. 11. In this case, the acceleration level at $40^{\circ} \mathrm{C}$ is kept below $3.5 \mathrm{~m} / \mathrm{s}^{2}$, and at $0^{\circ} \mathrm{C}$ the maximum acceleration attains $3.85 \mathrm{~m} / \mathrm{s}^{2}$, which corresponds to a reduction of $37.2 \%$. Figs. $13 \mathrm{~b}$, (c) and (d) show the acceleration envelopes of the retrofitted bridge at different temperatures and shear areas of VED. As it can be observed, the optimal dimension of VED area at $0^{\circ} \mathrm{C}(0.02$ $\mathrm{m}^{2}$ ) that leads to the minimum envelope shown in red line, is not optimal at $20^{\circ} \mathrm{C}$ nor at $40^{\circ} \mathrm{C}$. A similar behaviour of the damping system can be observed at $40^{\circ} \mathrm{C}$ (Fig. 13c), where the optimum VED shear area and the selected value for the retrofitting system are not coincident. The best performance of the damping system is attained at $20^{\circ} \mathrm{C}$, since the selected VEDs area $\left(0.12 \mathrm{~m}^{2}\right)$ is close to the optimum value $\left(0.14 \mathrm{~m}^{2}\right)$.

In what concerns the economic feasibility, the cost of the proposed retrofitting solution was compared to the cost of demolishing and installing a new deck (classical solution) in this particular example, concluding that the proposed damping system is economically feasible. 


\section{SUMMARY AND CONCLUSIONS}

In the present study the authors present a retrofitting system based on viscoelastic dampers (VEDs) which is capable of reducing the inadmissible accelerations of existing simply supported railway bridges under the circulation of modern high-speed traffic.

The VEDs are modelled using an advanced non-linear formulation based on fractional derivatives, which was previously proposed and used by Tsai and Lee [23] to study the energy-absorbing capacities in structures during earthquakes. A specific predictor-corrector algorithm has been developed in order to integrate numerically the equations of motion of the bridge deck, modelled as a simply-supported Euler-Bernoulli beam, along with the corresponding retrofitting system.

As an example of the application of VEDs to the retrofit of railway bridges, the dynamic behavior of a simply supported, single-track bridge due to the passing of high-speed trains is numerically evaluated with a view to assessing the effectiveness of the retrofitting system. Firstly, a sensitivity analysis of this system has led to a dimensioning procedure of the damping system, able to estimate the main dimensions of the auxiliary beams and VEDs in a first approach. Subsequently, an analysis is carried out with a view to discovering whether the retrofitting system keeps the maximum accelerations below the Serviceability limits for every temperature in the range of interest. If this is not accomplished, the damping system is redimensioned following an iterative process until the maximum accelerations satisfy the Serviceability Limits. The numerical results show that the maximum vertical acceleration can be drastically decreased by using a proper combination of auxiliary beams and VEDs in an outdoor environment. In this example, only one VED per beam is proposed, but the dampers could also be distributed along the length of the beams. 
Finally, it should be pointed out that the proposed retrofit solution can be feasible from an economical point of view.

\section{ACKNOLEDGEMENTS}

The authors wish to express their gratitude to the Spanish Ministry of Public Works for the financial support received in the framework of Research Project number 80021/A04.

\section{REFERENCES}

[1] Aprile A., Benedetti A. (1999). "Implicit dynamic analysis of VE-damped structures using Maxwell parallel systems”, Engineering Computations, Vol 16, No. 3, 374-396.

[2] Bagley, P.J., Torvik. (1986). On the fractional calculus model of viscoelastic behaviour, Journal of Rheology, Vol 30, No.1, 133-155.

[3] Chang K.C., Soong T.T., Oh S.T., Lai M.L. (1992). “Ambient temperature on a viscoelastically damped structure", Journal of Structural Engineering, ASCE, 118(7), 19551973.

[4] Choo J.F., Koh H.M., Kang S.C.,Kim B.S. (2003). "Vibration control of long-span highspeed railway bridges under periodic moving loading using viscoelastic dampers", Structures for high-speed railway transportation, International association for bridge and structural engineering, Antwerp (Belgium).

[5] European Committee for Standarisation (CEN), (2002). Eurocode: Basis of Structural Design.Annex A2: Application for bridges. Final PT Draft EN 1990 pr Annex A2 (preEuropean Standard)

[6] Frýba, L. (1999). "Dynamics of solids and structures under moving loads", Thomas Telford, London. 
[7] Frýba L. (2004) "Dynamic behaviour of bridges due to high-speed trains", Workshop Bridges for High-Speed Railways, Porto, 137-158.

[8] Galucio A. C., Deü, J.-F., Ohayon R., (2004). "Finite element formulation of viscoelastic sándwich beams using fraccional derivative operators", Computacional Mechanics, 33, 282291.

[9] Jones, David L.G. (2001). Handbook of viscoelastic vibration damping, John Wiley \& Sons.

[10] Koh C.G., Kelly, J.M. (1990) "Application of fractional derivatives to seismic analysis of base-isolated models", Earthquake Engineering and Structural Dynamics, 19, 229-241.

[11] Kwon H.C., Kim M.C., Lee I.W. (1998). "Vibration control of bridges under moving loads", Computers \& Structures, 66, 473-480.

[12] Mahmoodi P., Robertson L.E., Yontar M., Moy C., Feld L. (1987). "Performance of viscoelastic dampers in World Trade Center towers”, Proc. Structures Congress, Orlando, Florida, 632-644.

[13] Mancel F., Cedypia. (1999). "Analytical software for calculating dynamic effects on railway bridges", Proceedings of the Fourth European Conference on Structural Dynamics (Eurodyn '99), Prague, Vol. 2, 675-680.

[14] Martínez-Rodrigo M.D. (2009). Atenuación de vibraciones resonantes en puentes de ferrocarril de Alta Velocidad mediante amortiguadores fluido viscosos, Tesis Doctoral. Universidad Politécnica de Valencia.

[15] Martínez-Rodrigo M.D., Lavado J., Museros P. (2010), "Dynamic performance of existing high-speed railway bridges under resonant conditions retrofitted with fluid viscous dampers”, Engineering Structures, 32, 808-828. 
[16] Martínez-Rodrigo M.D., Museros P. (2011). “Optimal design of passive viscous dampers for controlling the resonant response of orthotropic plates under high-speed moving loads", Journal of Sound and Vibration, 330, 1328-1351.

[17] Moliner E., Museros P., Castillo-Linares A. (2007). Retrofit of railway bridges for highspeed traffic using discrete viscoelastic dampers. Proceedings of COMPDYN 2007, Computational Methods in Structural Dynamics and Earthquake Engineering, Rethymno, Crete, Greece, June 13-16.

[18] Museros P., Alarcón E. (2005). "Influence of the second bending mode on the response of high-speed bridges at resonance", Journal of Structural Engineering, 131, 405-415.

[19] Museros P., Martínez-Rodrigo M.D. (2007). "Vibration control of simple supported beams under moving loads using fluid viscous dampers", Journal of Sound and Vibration, $300,292-315$.

[20] Nielsen E.J., Lai M.L., Soong T.T., Kelly J.M. (1994) "Viscoelastic damper overview for seismic and wind applications", Proceedings of the First World Conference on Structural Control, Vol. 3, 42-51.

[21] Oliveto G., Santini A., Tripodi E., (1997)“Complex modal analysis of a flexural vibrating beam with viscous end conditions", Journal of Sound and Vibration 200, 327-345. [22] Samali, B., Kwok, K.C.S., (1995), "Use of viscoelastic dampers in reducing wind and earthquake induced motion of building structures“, Engineering Structures, 17 (9), 639-654. [23] Tsai C.S., Lee H.H. (1993). Applications of viscoelastic dampers to high-rise buildings, Journal of Structural Engineering, Vol 119, No.4.

[24] Wang J.F., Lin C.C., Chen B.L. (2003). "Vibration supression for high-speed railway bridges using tuned mass dampers", International Journal of Solids and Structures, 40, 465491. 
[25] Yang I.B., Yau J.D., Hsu L.C. (1997). "Vibration of simple beams due to trains moving at high speeds", Engineering Structures, 19, 936-944. 


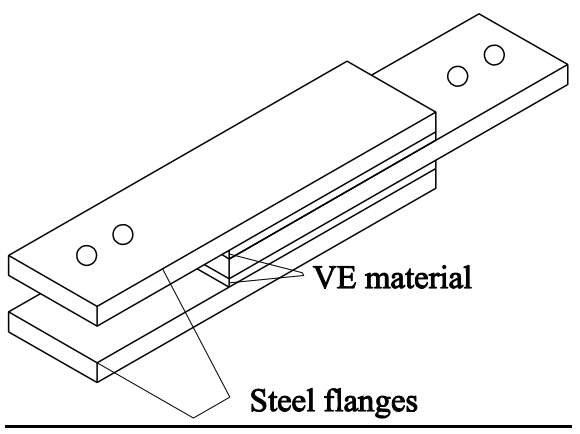

Fig. 1. Viscoelastic damper

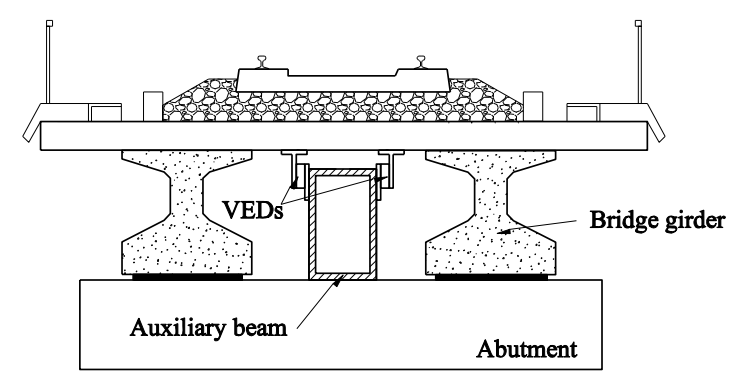

Fig. 2. Retrofit configuration

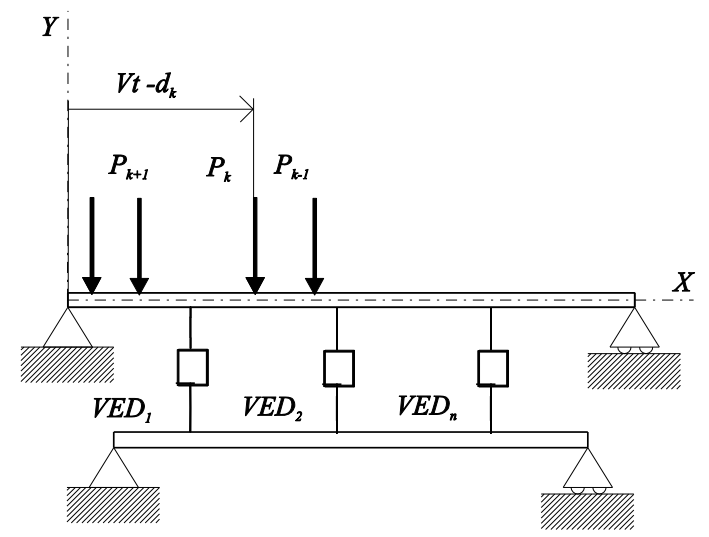

Fig. 3. Bidimensional model of the retrofitted bridge 

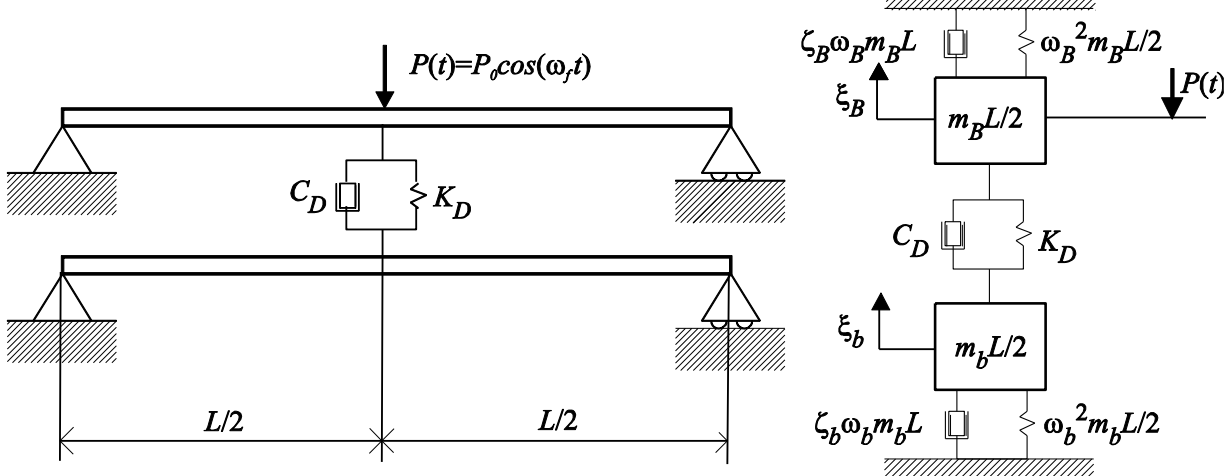

Fig. 4. Representation of the first flexural modes of bridge and auxiliary beam in modal space coordinates. Equivalent 2-DOF system
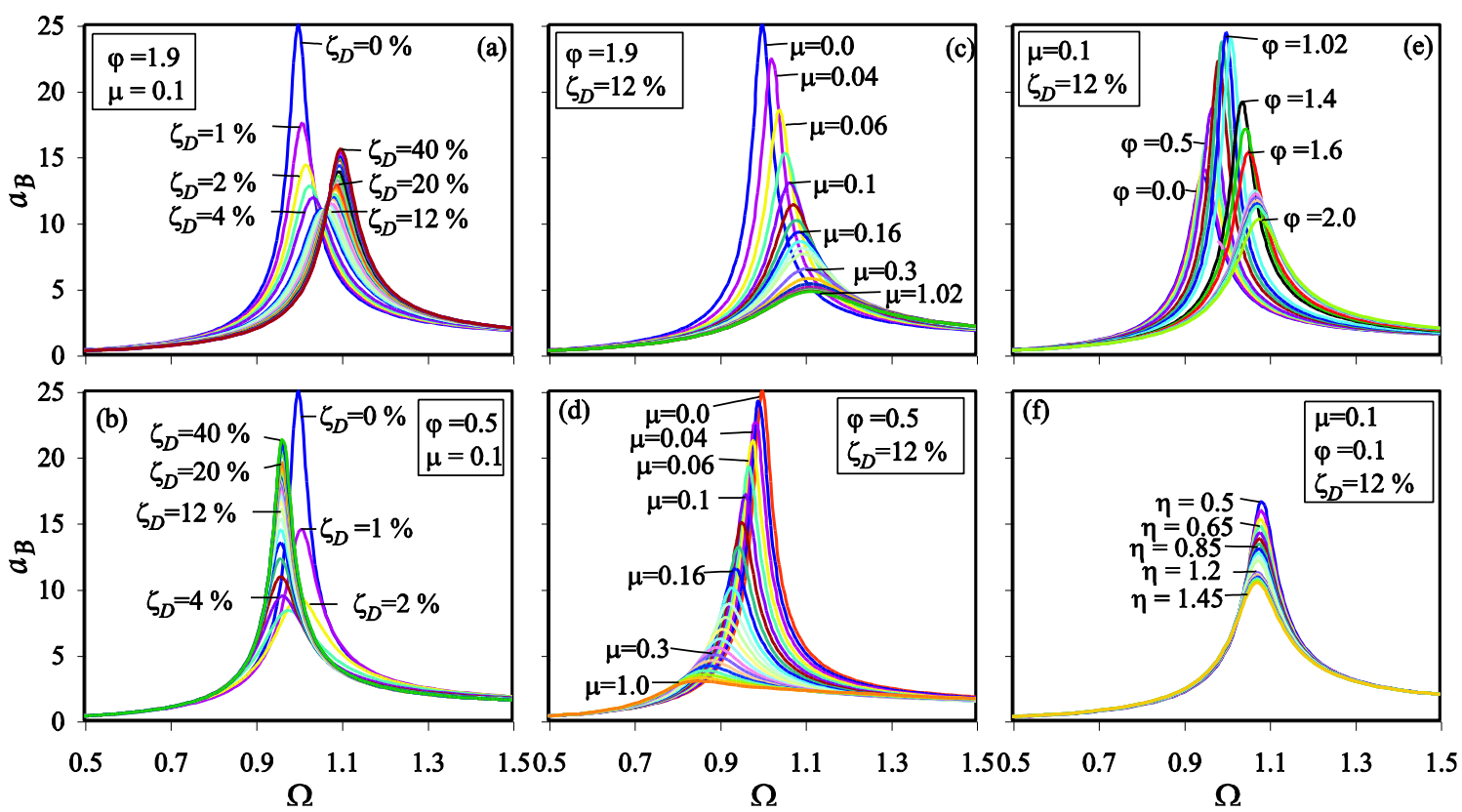

Fig. 5. Main beam acceleration $a_{B}$ versus $\Omega$ for different values of $\varphi, \mu, \zeta_{D}$ and $\eta$ 


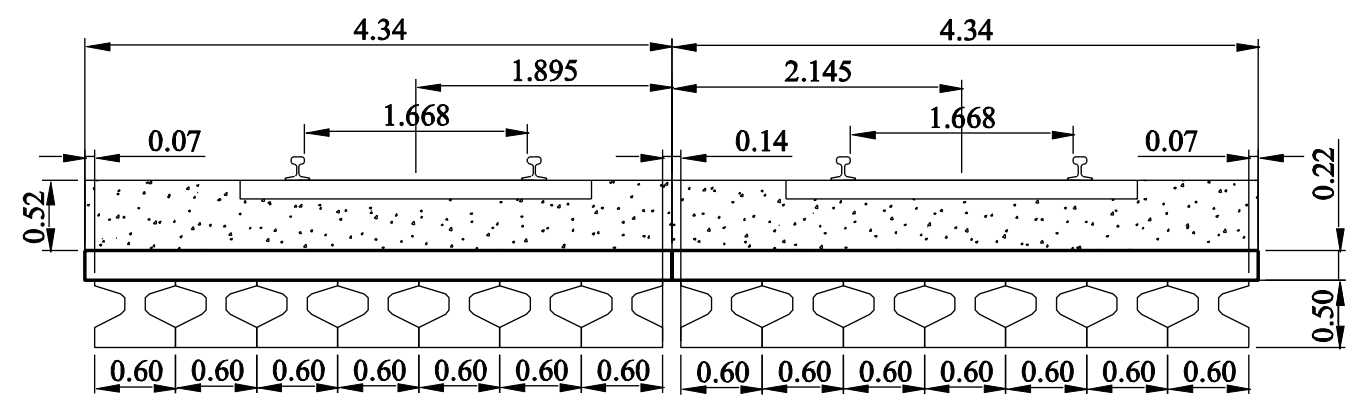

Fig. 6. Cross-section of Vinival bridge. Units of the figure (m)

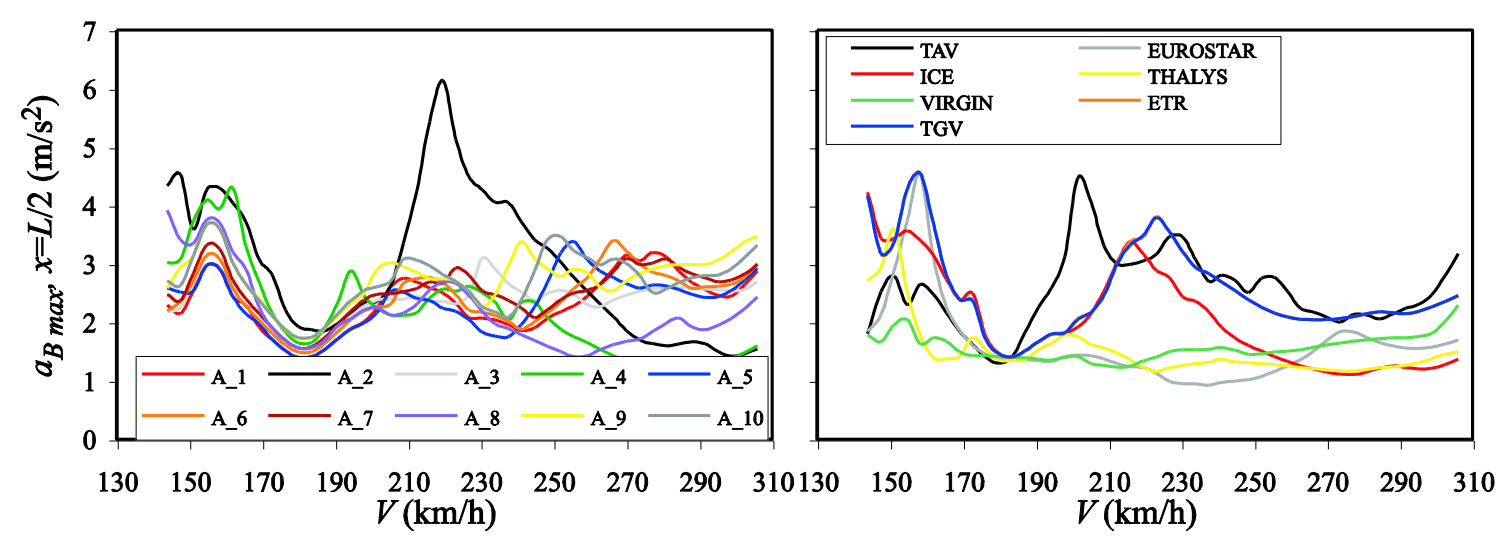

Fig. 7. Maximum vertical acceleration at mid span

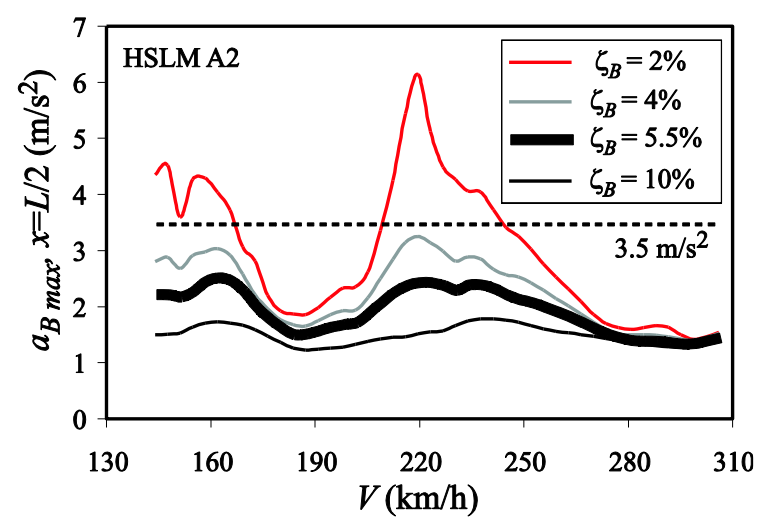

Fig. 8. Maximum vertical acceleration at mid span by increasing modal damping ratio $\zeta_{B}$ 


\begin{tabular}{|l|c|}
\hline \multicolumn{2}{|c|}{ Fractional VED model parameters [16] } \\
\hline$A_{0}(\mathrm{~Pa})$ & $7.0741 \cdot 10^{4}$ \\
$\mu$ & 3 \\
$\alpha$ & 0.6 \\
$\beta \quad\left(\mathrm{m}^{2} / \mathrm{N}\right)$ & $1.4504 \cdot 10^{-7}$ \\
$\theta \quad\left(\mathrm{N} /\left(\mathrm{m}^{2{ }^{\circ}} \mathrm{C}\right)\right)$ & $7.3774 \cdot 10^{5}$ \\
$T_{0}\left({ }^{\circ} \mathrm{C}\right)$ & 28 \\
\hline
\end{tabular}

VED properties at $20^{\circ} \mathrm{C}, 12.8 \mathrm{~Hz}$ and $\gamma=0.05$

\begin{tabular}{|l|c|}
\hline $\boldsymbol{G}_{\boldsymbol{E}}(\mathrm{MPa})$ & 4.448 \\
$\eta$ & 1.19 \\
\hline
\end{tabular}

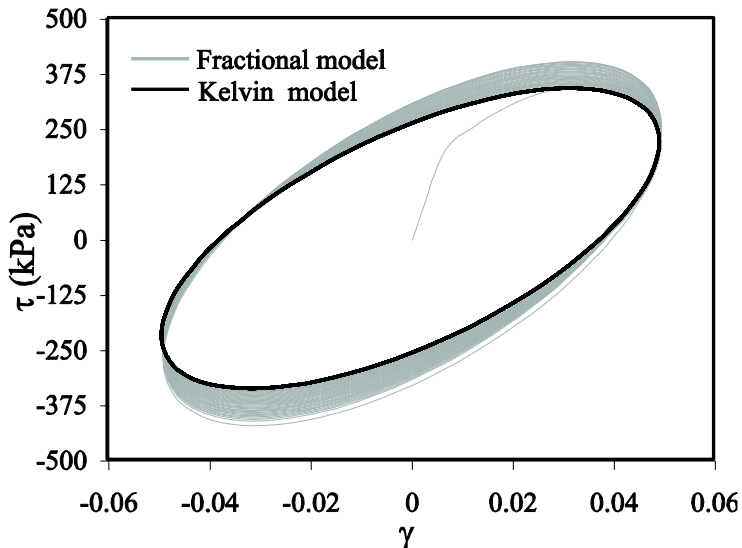

Fig. 9. VED model parameters and hysteretic behaviour while strain is $0.05 \cdot \sin \left(\omega_{B} t\right)$, at $20^{\circ} \mathrm{C}$
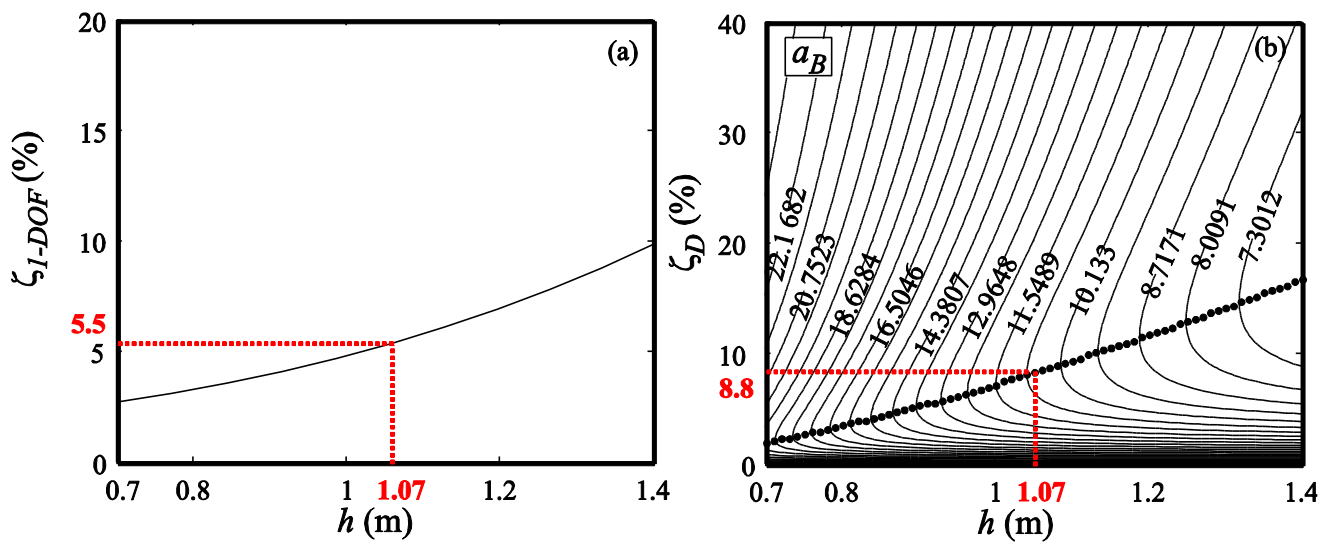

Fig. 10. Selection of the minimum pair $h-\zeta_{D}$ from the structural damping requirements
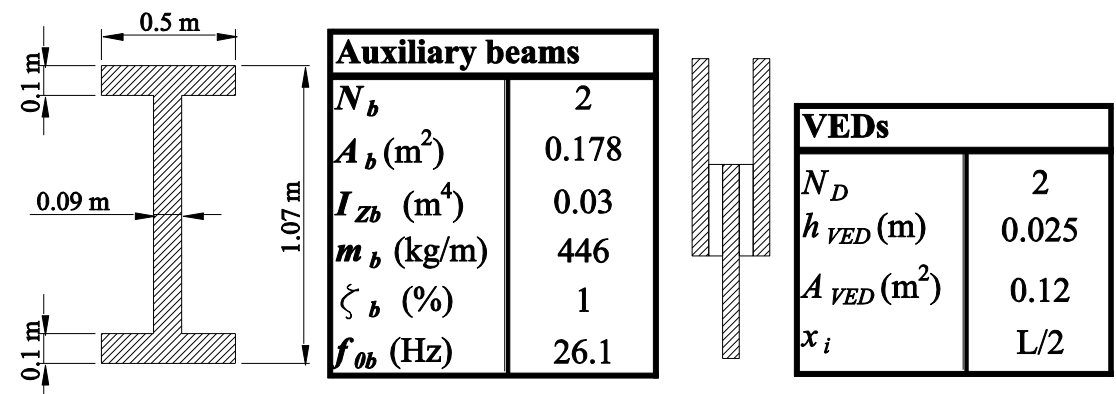

Fig. 11. Retrofitting elements 


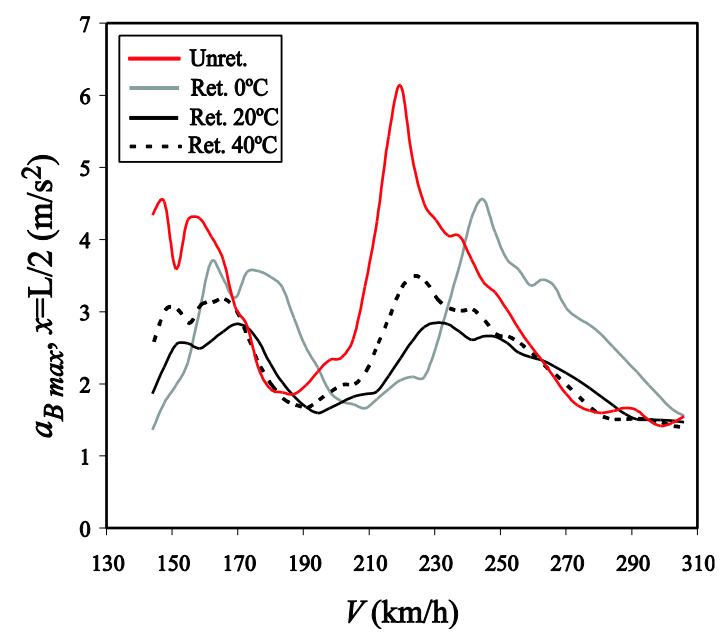

Fig. 12. Maximum retrofitted vertical acceleration at mid span. $h=1.07 \mathrm{~m}$
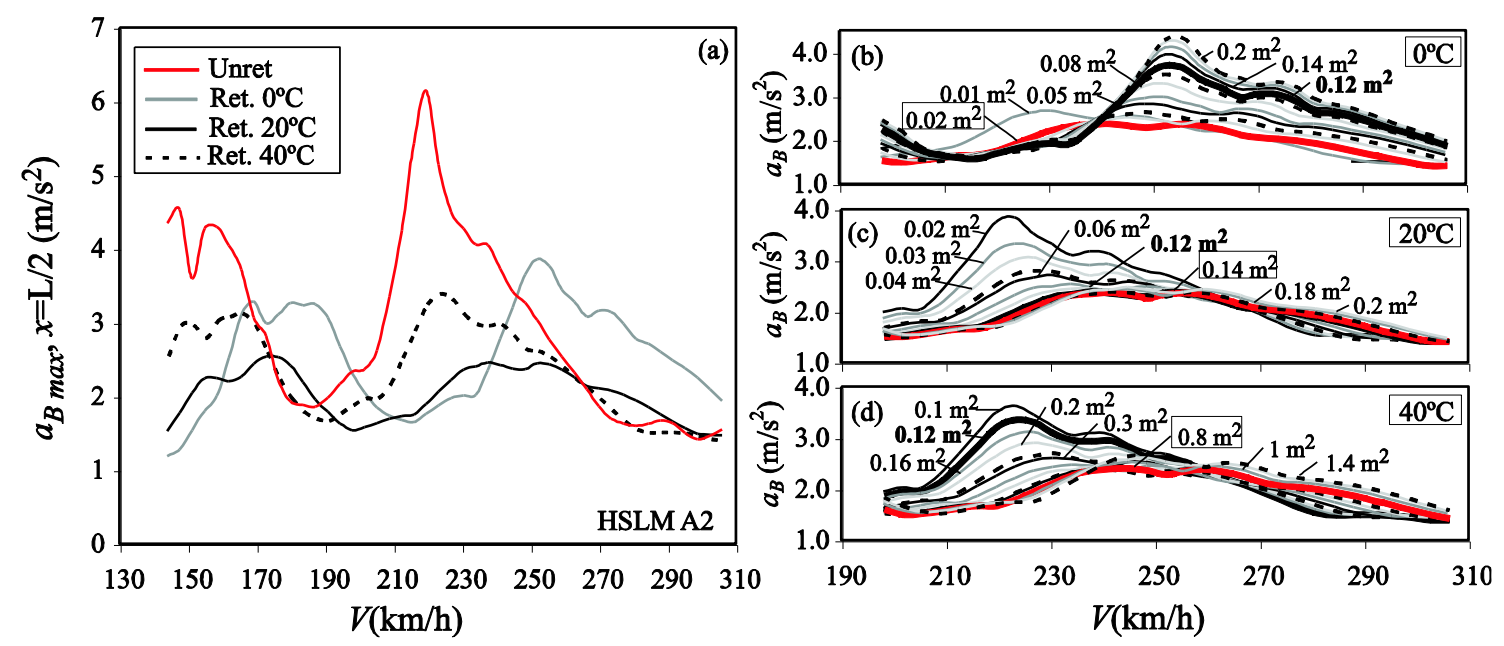

Fig. 13. Maximum retrofitted vertical acceleration at mid span. $h=1.2 \mathrm{~m}$ 


\begin{tabular}{|l|l|}
\hline Length, $\boldsymbol{L}(\mathrm{m})$ & 9.70 \\
\hline Mass per unit length, $\boldsymbol{m}_{\boldsymbol{B}}(\mathrm{kg} / \mathrm{m})$ & 9754 \\
\hline Inertia, $\boldsymbol{I}_{\boldsymbol{Z} \boldsymbol{B}}\left(\mathrm{m}^{4}\right)$ & 0.159 \\
\hline Young modulus, $\boldsymbol{E}_{\boldsymbol{B}}(\mathrm{Pa})$ & $3.610^{10}$ \\
\hline Natural frequency, $\boldsymbol{f}_{\boldsymbol{B}}(\mathrm{Hz})$ & 12.8 \\
\hline Modal damping ratio, $\boldsymbol{\zeta}_{\boldsymbol{B}}(\%)$ & 2 \\
\hline
\end{tabular}

Table 1. Mechanical properties of Vinival bridge 